\title{
Performance optimization in electro- discharge machining using a suitable multiresponse optimization technique
}

\author{
I. Nayak $^{\mathrm{a}^{*}}$, J. Rana ${ }^{\mathrm{b}}$ and A. Parida ${ }^{\mathrm{c}}$
}

\begin{abstract}
a.Ph.D. Scholar, Department of Mechanical Engineering, Veer Surendra Sai University of Technology, Burla, Odisha, India ${ }^{b}$ Professor, Department of Mechanical Engineering, Veer Surendra Sai University of Technology, Burla, Odisha, India ${ }^{c}$ M.Tech Student, Department of Mechanical Engineering, Veer Surendra Sai University of Technology, Burla, Odisha, India

\begin{tabular}{l}
\hline C H R O N I C L E \\
\hline Article history: \\
Received October 3, 2016 \\
Received in revised format: \\
October 22, 2016 \\
Accepted December 8, 2016 \\
Available online \\
December 92016 \\
\hline Keywords: \\
Multi response optimization \\
techniques \\
MRR \\
TWR \\
SR \\
ANOVA technique
\end{tabular}

A B S T R A C T

In the present research work, four different multi response optimization techniques, viz multiple response signal-to-noise (MRSN) ratio, weighted signal-to-noise (WSN) ratio, Grey relational analysis (GRA) and VIKOR (VlseKriterijumska Optimizacija I Kompromisno Resenje in Serbian) methods have been used to optimize the electro-discharge machining (EDM) performance characteristics such as material removal rate (MRR), tool wear rate (TWR) and surface roughness (SR) simultaneously. Experiments have been planned on a D2 steel specimen based on L9 orthogonal array. Experimental results are analyzed using the standard procedure. The optimum level combinations of input process parameters such as voltage, current, pulse-on-time and pulse-off-time, and percentage contributions of each process parameter using ANOVA technique have been determined. Different correlations have been developed between the various input process parameters and output performance characteristics. Finally, the optimum performances of these four methods are compared and the results show that WSN ratio method is the best multiresponse optimization technique for this process. From the analysis, it is also found that the current has the maximum effect on the overall performance of EDM operation as compared to other process parameters.
\end{abstract}

\section{Introduction}

Electro-discharge machining (EDM) is a non-conventional machining process used for machining various difficult-to-machine materials having a higher degree of utility in the field of aviation, automobile and electronics. The main advantage of EDM is its capability to produce complex shapes with high degree of accuracy. In the past years, several researchers have studied the influence of various process parameters such as current intensity, pulse on time, pulse off time, gap voltage, rotational speed on material removal rate (MRR), surface roughness (SR), tool wear rate (TWR) and relative electrode

\footnotetext{
* Corresponding author.

E-mail address: ipsitan23@gmail.com (I. Nayak)

(C) 2017 Growing Science Ltd. All rights reserved. doi: $10.5267 /$ j.ds1.2016.12.002
}

(C) 2017 Growing Science Ltd. All rights reserved. 
wear ratio (REWR). Tzeng and Chiu (2003) employed Taguchi's dynamic experiment coupled with two-phase design strategy for effective and efficient development of a robust high speed and high quality EDM process leading to high MRR. Singh et al. (2004) optimized the various EDM process parameters such as material removal rate (MRR), tool wear rate (TWR), taper (T), radial overcut (ROC) and surface roughness (SR) using Grey Relational Analysis (GRA) technique. Wang et al. (2006) proposed a novel truing and dressing method, namely dry electrical discharge (ECD) assisted truing and dressing to overcome the shortcomings associated with conventional mechanical dressing methods. Chiang et al. (2007) presented a methodology for modelling and analysis of rapidly resolidified layer of spheroidal graphite (SG) cast iron in EDM process using the response surface methodology (RSM). Tzeng and Chen (2007) applied fuzzy logic analysis coupled with Taguchi's method to optimize the precision and accuracy of the high speed EDM process. Mandal et al. (2007) studied the influence of current, pulse on time and pulse off time on MRR and tool wear using multi-objective optimization model. Dhar et al. (2007) studied the effect of current, pulse on time and air gap voltage on MRR, TWR and $\mathrm{ROC}$ in electric discharge machining of $\mathrm{Al}-4 \mathrm{Cu}-6 \mathrm{Si}$ alloy-10 $\mathrm{wt} \% \mathrm{SiC}_{\mathrm{p}}$ composites. Rao et al. (2008) developed a hybrid model using artificial neural network and genetic algorithm to optimize the surface roughness in EDM. Yang et al. (2009) proposed an optimized methodology using simulated annealing technique for the selection of best process parameters in electro discharge machining. Lee and Liu (2009) presented a case study to optimize the recast layer thickness and induced stress in EDM drilling. Results showed that with reduction in relative stability coefficient of the discharge duty ratio, the recast layer thickness and induced stress were increased. Joshi and Pande (2010) performed experiments on die-sinking EDM process to study the MRR and crater shapes produced during machining. Puertas and Luis (2012) analyzed the influence of intensity of current, pulse duration, duty cycle, open circuit voltage and dielectric flushing pressure on the quality of EDM machining of $\mathrm{B}_{4} \mathrm{C}$ and WC-Co ceramics. Majumder (2013) proposed a multi-objective optimization technique based on fuzzy logic to determine the optimal machining conditions during the machining of AISI $316 \mathrm{LN}$ stainless steel. Mohanty et al. (2014) proposed a hybrid optimization technique (Response surface methodology (RSM) coupled with Multi-Objective Particle Swarm Optimization (MOPSO)) for optimizing EDM parameters during the machining of Inconel 718 alloy. Balasubramanian and Senthivelan (2014) adopted response surface methodology (RSM) and analysis of variance (ANOVA) to identify the significance of peak current, pulse on time, dielectric pressure and tool diameter on MRR, TWR and SR. Dewangan et al. (2014) used L8 orthogonal array based on Taguchi's design to optimize the surface integrity like surface crack density, white layer thickness and surface roughness of AISI P20 steel while machined by EDM using graphite tool. Raja et al. (2015) implemented Firefly algorithm (FA) to study the effect of current and pulse-on-time on the surface roughness and machining time while machining hardened die steel.

It is observed from the study of past research works that there are many multiresponse optimization techniques being used by the researchers, out of which the multiresponse signal to noise (MRSN) ratio method, weighted signal to noise (WSN) ratio method (Shiau, 1990; Tai et al., 1992), grey relational analysis (GRA) method (Singh et al., 2004), and VIKOR method (Tong et al., 2007; Nayak and Rana, 2016) are quite simpler as compared to other techniques (Chiang et al., 2007; Mandal et al., 2007; Sengottuvel et al., 2013; Teimouri and Baseri, 2014; Das et al., 2014). Those optimization techniques make use of complex statistical procedures and softwares, which may be inconvenient to be used by the industrial personnel having little knowledge of software and statistics.

This paper describes the comparative study of above four multiresponse optimization techniques (chosen due to their computational simplicity) to predict the machinability characteristics of EDMed $\mathrm{D}_{2}$ steel using Taguchi's $\mathrm{L}_{9}$ orthogonal array in context to responses such as material removal rate, tool wear rate and surface roughness. Also, the influence of machining parameters on responses are analyzed using ANOVA technique and finally prediction models have also been presented through multiple regression analysis which are further verified with confirmatory experimental results. 


\section{Comparative study among MRSN, WSN, GRA and VIKOR}

As stated above, the main objective of the present paper is to determine a best multiresponse optimization technique among the four simple multiresponse optimization techniques such as MRSN, WSN, GRA and VIKOR.

For the comparative study of the above four multi-response optimization techniques, the following three common steps (step-1 to step-3) are followed: (Nayak \& Rana, 2016)

Step 1: Conversion of the multiple responses into a single process performance index (PPI) for optimization.

Step 2: Determination of the optimal level combination and significant factors using ANOVA technique.

Step 3: Validation of the optimal level combination using confirmatory experiment.

\subsection{Determination of single process performance index (PPI) value}

\subsubsection{MRSN ratio method}

Step 1: The loss function ( $L i j)$ corresponding to each performance characteristic (Nayak \& Rana, 2016) is first normalized or scaled as follows,

$$
S_{i j}=L_{i j} / \bar{L}_{j}
$$

where, $S_{i j}$ is the scaled quality loss for $j$ th response in $i$ th trial, $\overline{\mathrm{L}}_{\mathrm{j}}=\frac{1}{\mathrm{~m}} \sum_{\mathrm{i}=1}^{\mathrm{m}} \mathrm{L}_{\mathrm{ij}}$ is the average quality loss for the $j$ th response.

Step 2: Based on the weighing method, the total loss function $\left(T L_{i}\right)$ in the $i$ th experiment is calculated using the following formula.

$$
T L_{i}=\sum_{i=1}^{m} w_{j} S_{i j}
$$

where, $w_{j}$ is the weighing factor for the $j$ th performance characteristic, decided by the analyzer, and $\sum_{j=1}^{p} w_{j}=1$.

Step 3: The total loss function is then transformed into a multi-response S/N (MRSN) ratio, using the following formula.

$$
\operatorname{MRSN}_{i}=-10 \log _{10}\left(T L_{i}\right) .
$$

\subsubsection{WSN method}

Step 1: The $\mathrm{S} / \mathrm{N}$ ratio values $\left(\eta_{i j}\right)$ for all the responses are first obtained as follows:

$$
\eta_{i j}=-10 \log _{10} L_{i j}
$$

Step 2: The $\mathrm{S} / \mathrm{N}$ ratio values are then normalized as follows:

(a) For larger the better: $Y_{i j}=\frac{\eta_{i j}-\eta_{j}^{\min }}{\eta_{j}^{\max }-\eta_{j}^{\min }}$,

(b) For smaller the better: $Y_{i j}=\frac{\eta_{j}^{\max }-\eta_{i j}}{\eta_{j}^{\text {max }}-\eta_{j}^{\min }}$, 
where, $Y_{i j}$ is the normalized $\mathrm{S} / \mathrm{N}$ ratio or scaled $\mathrm{S} / \mathrm{N}$ ratio value for $j$ th $(j=1,2 \ldots \mathrm{p})$ response in $i$ th trial, $\eta_{j}^{\min }=\min \left\{\eta_{1 j}, \eta_{2 j} \ldots . . \eta_{\mathrm{m} j}\right\}$ and $\eta_{j}^{\max }=\max \left\{\eta_{1 j}, \eta_{2 j} \ldots . . \eta_{\mathrm{m} j}\right\}$. By using Eq. 5 and Eq. 6 , the $\mathrm{S} / \mathrm{N}$ ratio values of all the performance characteristics are scaled into $(0,1)$ interval.

Step 3: Determination of the WSN value for the ith trial using the following equation:

$\operatorname{WSN}_{i}=\sum_{j=1}^{p} w_{j} Y_{i j}$

where, $w_{j}$ is the assigned weight for the $j$ th response, and $\sum_{j=1}^{p} w_{j}=1$.

\subsubsection{GRA method}

Step 1: The $\mathrm{S} / \mathrm{N}$ ratio values for all the performance characteristics $\left(\eta_{i j}\right)$ are first computed using Eq. 4

Step 2: Then the $\mathrm{S} / \mathrm{N}$ ratio values are normalized or scaled between zero and one using Eq. 5 and Eq. 6 (as applicable).

Step 3: The grey relational coefficients $\left(\gamma_{i j}\right)$ is then computed as follows,

$$
\gamma_{i j}=\frac{\Delta_{j}^{\min }+\xi \Delta_{j}^{\max }}{\Delta_{i j}+\xi \Delta_{j}^{\text {max }}}
$$

where, $\Delta_{i j}=\left|1-Y_{i j}\right|, \Delta_{j}^{\text {min }}=\min \left\{\Delta_{1 j}, \Delta_{2 j}, \ldots, \Delta_{m j}\right\}$ i.e. the smallest value of $\Delta_{i j}, \Delta_{j}^{\max }=\max \left\{\Delta_{1 j}\right.$, $\left.\Delta_{2 j}, \ldots, \Delta_{m j}\right\}$ i.e. the maximum value of $\Delta_{i j}$, and $\xi$ is the distinguishing coefficient $(\xi \in[0,1])$ and its value is usually taken as 0.5 .

Step 4: Then, the grey relational grade $\left(G R G_{i}\right.$, a weighted sum of grey relational coefficients) for $i$ th trial is calculated as follows,

$$
G R G_{i}=\sum_{j=1}^{p} w_{j} \gamma_{i j}
$$

where, $w_{j}$ is the weight assigned to the $j$ th response, and $\sum_{j=1}^{p} w_{j}=1$.

\subsubsection{VIKOR method}

The VIKOR index value for each experiment can be computed using the following steps:

Step 1: Computation of the $\mathrm{S} / \mathrm{N}$ ratio $\left(\eta_{i j}\right)$ values for all the performance characteristics, using Eq. 4

Step 2: Determination of the scaled $\mathrm{S} / \mathrm{N}$ ratio values for all the responses for all the trials, $Y_{i j}$ using Eq.5

Step 3: The ideal solution $\left(A^{*}\right)$ and the negative ideal solution $\left(A^{-}\right)$are determined as follows:

$$
\begin{aligned}
& A^{*}=\max \left\{Y_{i j} \mid i=1,2, \ldots, m\right\}=\left\{Y_{1}^{*}, Y_{2}^{*}, \ldots ., Y_{p}^{*}\right\} \\
& A^{-}=\min \left\{Y_{i j} \mid i=1,2, \ldots, m\right\}=\left\{Y_{1}^{-}, Y_{2}^{-}, \ldots ., Y_{p}^{-}\right\}
\end{aligned}
$$

Step 4: The utility and regret measure for each experimental trial are calculated as follows,

$$
\begin{aligned}
S_{i} & =\sum_{j=1}^{n} w_{j}\left(Y_{j}^{*}-Y_{i j}\right) /\left(Y_{j}^{*}-Y_{j}^{-}\right) \\
R_{i} & =\max _{j}\left[w_{j}\left(Y_{j}^{*}-Y_{i j}\right) /\left(Y_{j}^{*}-Y_{j}^{-}\right)\right]
\end{aligned}
$$

where, $w_{j}$ is the weight assigned to the $j$ th performance characteristic and $\sum_{j=1}^{p} w_{j}=1$.

Step 5: Calculation of the VIKOR index for the $i$ th experiment, i.e. 
$Q_{i}=v\left[\frac{S_{i}-S^{*}}{S^{-}-S^{*}}\right]+(1-v)\left[\frac{R_{i}-R^{*}}{R^{-}-R^{*}}\right] ; i=1,2, \ldots \ldots, m$

where, $S^{*}=\min _{i} S_{i}, S^{-}=\max _{i} S_{i}, \mathrm{R}^{*}=\min R_{i}, R^{-}=\max _{i} R_{i}$ and $v$ is the weight of the maximum group utility and usually, it is set to 0.5 [1].

\section{Plan of experiment}

A case study on electro discharge machining was performed by conducting a series of experiments and all the results were analyzed by following the standard procedures as stated earlier to find out the most suitable multiresponse optimization technique for the given operation.

\subsection{Experimental works}

\subsubsection{Work Material and Electrode}

The work material selected for this research work was $\mathrm{D}_{2}$ tool steel whose chemical composition and mechanical properties are given in Table 1 and Table 2, respectively. For the experimental work, cylindrical bar of $\mathrm{D}_{2}$ steel with diameter of $45 \mathrm{~mm}$ and height of $12 \mathrm{~mm}$ was machined on a CNC EDM machine. A copper rod of diameter $10 \mathrm{~mm}$ was used as cutting tool (electrode). Prior to the actual machining, surface grinding was done on both the faces of work material to provide two flat and polished surfaces.

\section{Table 1}

Chemical composition of $\mathrm{D}_{2}$ steel

\begin{tabular}{lllllll}
\hline Element & $\mathrm{C}$ & $\mathrm{Si}$ & $\mathrm{Cr}$ & $\mathrm{Mo}$ & $\mathrm{V}$ & $\mathrm{Fe}$ \\
\hline Percentage (\%) & 1.5 & 0.3 & 12 & 0.8 & 0.9 & 84.5 \\
\hline
\end{tabular}

\section{Table 2}

Mechanical properties of workpiece material

\begin{tabular}{ll}
\hline Mechanical properties & Values \\
\hline Hardness (HRC) & 62 \\
Melting Point $\left({ }^{\circ} \mathrm{C}\right)$ & 1421 \\
Density $\left(\mathrm{kg} / \mathrm{m}^{3}\right)$ & $7.7 \times 1000$ \\
Poisson's ratio & $0.27-0.30$ \\
Elastic Modulus $(\mathrm{GPa})$ & $190-210$ \\
Modulus of elasticity $(\mathrm{GPa})$ & 210 \\
\hline
\end{tabular}

\subsubsection{Input process parameters}

In the present research work, four different input process parameters such as voltage (V), current (I), pulse on time $\left(\mathrm{T}_{\mathrm{on}}\right)$ and pulse off time $\left(\mathrm{T}_{\mathrm{off}}\right)$ were selected for conducting the experiments. Each parameter was varied in three levels, denoted by 1, 2, and 3 (i.e. low, medium, and high respectively). Table 3 indicates the factors and their levels. Experiments were planned according to Taguchi's L9 orthogonal array, which is shown in Table 4.

\section{Table 3}

Process parameters and their levels

\begin{tabular}{lllllll}
\hline S1 No. & Parameter & Unit & Symbol & Level 1 & Level 2 & Level 3 \\
\hline 1 & Voltage & Volt & A & 1 & 1.5 & 2 \\
2 & Current & Amp & B & 5 & 10 & 15 \\
3 & Pulse on time & $\mu$ s & C & 100 & 125 & 150 \\
4 & Pulse off time & $\mu$ s & D & 40 & 50 & 60 \\
\hline
\end{tabular}




\section{Table 4}

Layout of $\mathrm{L}_{9}$ orthogonal array

\begin{tabular}{|c|c|c|c|c|}
\hline Experiment number & $\mathrm{A}$ & $\mathrm{B}$ & $\mathrm{C}$ & $\bar{D}$ \\
\hline 1 & 1 & 1 & 1 & 1 \\
\hline 2 & 1 & 2 & 2 & 2 \\
\hline 3 & 1 & 3 & 3 & 3 \\
\hline 4 & 2 & 1 & 2 & 3 \\
\hline 5 & 2 & 2 & 3 & 1 \\
\hline 6 & 2 & 3 & 1 & 2 \\
\hline 7 & 3 & 1 & 3 & 2 \\
\hline 8 & 3 & 2 & 1 & 3 \\
\hline 9 & 3 & 3 & 2 & 1 \\
\hline
\end{tabular}

\subsubsection{Experimental details}

As stated earlier a round bar of $\mathrm{D}_{2}$ steel with diameter $45 \mathrm{~mm}$ and $12 \mathrm{~mm}$ height was taken as work material which was machined using a copper rod of $10 \mathrm{~mm}$ diameter as cutting tool (or electrode) in a MIC 432C CNC-EDM machine. Fig. 1 represents the experimental set up. The weight of the specimen as well as the electrode was measured repeatedly each time before and after the experiment with the help of a high precision digital balance. Nine sets of experiments were conducted on the above specimen by selecting nine different settings of input machining parameters. Machining time for each experiment was 5 mins.

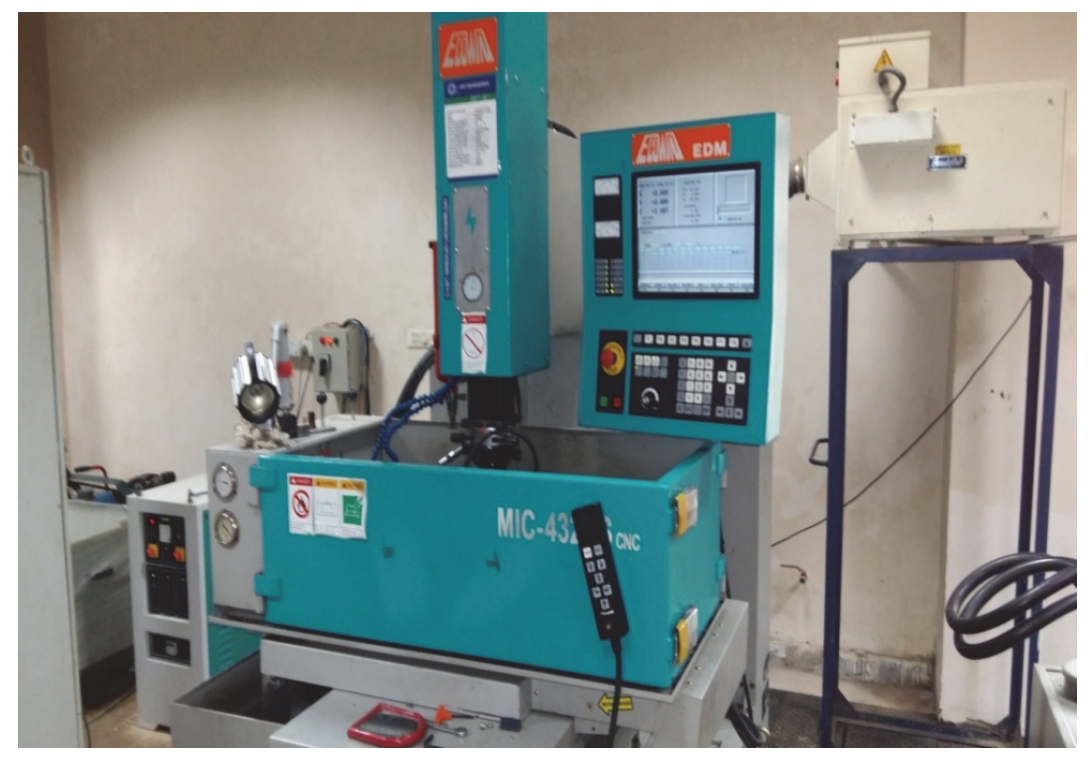

Fig. 1. CNC- EDM Machine

In the present research work, the responses measured are material removal rate (MRR), surface roughness $(\mathrm{Ra})$, and tool wear rate $(\mathrm{TWR})$. The MRR $(\mathrm{g} / \mathrm{min})$ and TWR $(\mathrm{g} / \mathrm{min})$ were calculated using the Eq. (15) and Eq. (16), respectively. While the surface roughness (Ra) was measured using a surface roughness tester.

Material removal rate, $M R R=\frac{w_{i}-w_{f}}{t} \mathrm{~g} / \mathrm{min}$

where, $w_{i}$ is the weight of the specimen before machining, $w_{f}$ is the weight of the specimen after machining and $t$ is the machining time.

Tool wear rate, $T W R=\frac{w_{t i}-w_{t f}}{t} \mathrm{~g} / \mathrm{min}$

where, $w_{t i}$ and $w_{t f}$ are the weight of the tool before and after machining respectively, and $t$ is the machining time. The experimental results are presented in Table 5. 
Table 5

Experimental results

\begin{tabular}{|c|c|c|c|c|c|c|c|}
\hline Expt. No. & Voltage (V) & Current (A) & $\mathrm{T}_{\text {on }}(\mu \mathrm{s})$ & $\mathrm{T}_{\text {off }}(\mu \mathrm{s})$ & $\operatorname{MRR}(\mathrm{g} / \mathrm{min})$ & TWR (g/min) & $\mathrm{SR}(\mu \mathrm{m})$ \\
\hline 1 & 1 & 5 & 100 & 40 & $3.8 \times 10^{-3}$ & $2.16 \times 10^{-3}$ & 12.178 \\
\hline 2 & 1 & 10 & 125 & 50 & 0.0722 & $3.6 \times 10^{-3}$ & 11.657 \\
\hline 3 & 1 & 15 & 150 & 60 & 0.1156 & $4.4 \times 10^{-3}$ & 10.847 \\
\hline 4 & 1.5 & 5 & 125 & 60 & 0.0384 & $4.6 \times 10^{-3}$ & 6.847 \\
\hline 5 & 1.5 & 10 & 150 & 40 & 0.0956 & $3.4 \times 10^{-3}$ & 8.064 \\
\hline 6 & 1.5 & 15 & 100 & 50 & 0.026 & $2.4 \times 10^{-3}$ & 13.791 \\
\hline 7 & 2 & 5 & 150 & 50 & 0.0412 & $2.4 \times 10^{-3}$ & 7.280 \\
\hline 8 & 2 & 10 & 100 & 60 & 0.0112 & $2.8 \times 10^{-3}$ & 9.793 \\
\hline 9 & 2 & 15 & 125 & 40 & 0.1624 & $4.4 \times 10^{-3}$ & 12.114 \\
\hline
\end{tabular}

\subsection{Results and Discussion}

This section represents the analysis of the experimental data given in Table 5 by using the four different multi response optimization techniques described in the previous section. In order to estimate the effect of various input machining parameters on the performance characteristics, analysis of variance (ANOVA) is employed on the PPI values and based on the results of ANOVA analysis, optimal machining parameters have been obtained and verified with the confirmatory experiments.

\subsubsection{Analysis of the experimental data}

In the current research work, the material removal rate (MRR) is analyzed using the larger the better principle, and the tool wear rate (TWR) and the surface roughness $\left(\mathrm{R}_{\mathrm{a}}\right)$ are analyzed using smaller the better principle and the corresponding loss functions are calculated using standard equations (Nayak $\&$ Rana, 2016). In this present study, all the responses are given with equal priority. Table 6 represents the PPI values obtained in the four multi response optimization techniques by using the standard procedure stated earlier.

Table 6

PPI values for MRSN, WSN, GRA, and VIKOR method

\begin{tabular}{llccc}
\hline Expt. No. & MRSN & WSN & PPI value & GRG \\
\hline 1 & -4.9951 & 0.2741 & 0.4682 & 0.6602 \\
2 & 1.1148 & 0.7399 & 0.7782 & 0.7414 \\
3 & 0.4983 & 0.8359 & 0.6330 & 0.8993 \\
4 & 1.2407 & 0.5387 & 0.5768 & 0.8218 \\
5 & 2.8475 & 0.5642 & 0.6245 & 0.9206 \\
6 & 1.0491 & 0.5505 & 0.4331 & 0 \\
8 & 4.6801 & 0.2872 & 0.4501 \\
\hline
\end{tabular}

Since the experiment is based on orthogonal array, it is possible to separate out the mean MRSN ratio, WSN ratio, GRG, and VIKOR index of each input process parameter at different factor levels as given in Table 7. Larger values of MRSN, WSN, and GRG indicate better quality. However, a smaller value of VIKOR index gives the better quality (Tong et al., 2007). From this the optimal level combination can be easily determined. The optimal parameter combination of the factors $\mathrm{A}, \mathrm{B}, \mathrm{C}$ and $\mathrm{D}$ with respect to MRSN and VIKOR index is found to be $\mathrm{A}_{3} \mathrm{~B}_{2} \mathrm{C}_{3} \mathrm{D}_{2}$, whereas, the optimal parameter combination obtained for the WSN and GRA method is $\mathrm{A}_{1} \mathrm{~B}_{3} \mathrm{C}_{2} \mathrm{D}_{1}$.

Table 7

Level averages of the factors on different PPI values

\begin{tabular}{ccccccccccccc}
\hline Factors & MRSN & \multicolumn{3}{c}{ WSN } & \multicolumn{3}{c}{ GRG } & \multicolumn{3}{c}{ VIKOR index } \\
& Level 1 & Level 2 & Level 3 & Level 1 & Level 2 & Level 3 & Level 1 & Level 2 & Level 3 & Level 1 & Level 2 & Level 3 \\
\hline A & -1.1273 & 1.7124 & 1.9118 & 0.6166 & 0.5511 & 0.5289 & 0.6355 & 0.6114 & 0.5860 & 0.8802 & 0.6942 & 0.5320 \\
B & 0.3086 & 1.6396 & 0.5487 & 0.3667 & 0.5616 & 0.7684 & 0.5114 & 0.5624 & 0.7592 & 0.6073 & 0.5837 & 0.9155 \\
C & -0.9965 & 0.8181 & 2.6753 & 0.4018 & 0.7324 & 0.5624 & 0.5143 & 0.7227 & 0.5960 & 0.8633 & 0.8299 & 0.4132 \\
D & -0.6829 & 2.2813 & 0.8985 & 0.5857 & 0.5259 & 0.5851 & 0.6399 & 0.5726 & 0.6204 & 0.7556 & 0.5540 & 0.7968 \\
\hline
\end{tabular}




\subsubsection{Analysis of variance}

Analysis of variance (ANOVA) is a well established statistical technique (Montgomery, 2001) used to identify the significance of input process parameters on the performance characteristics. Graphs of average MRSN ratio, WSN ratio, GRG and VIKOR index value obtained from Table 7 are represented in Figs. (3-6), respectively.

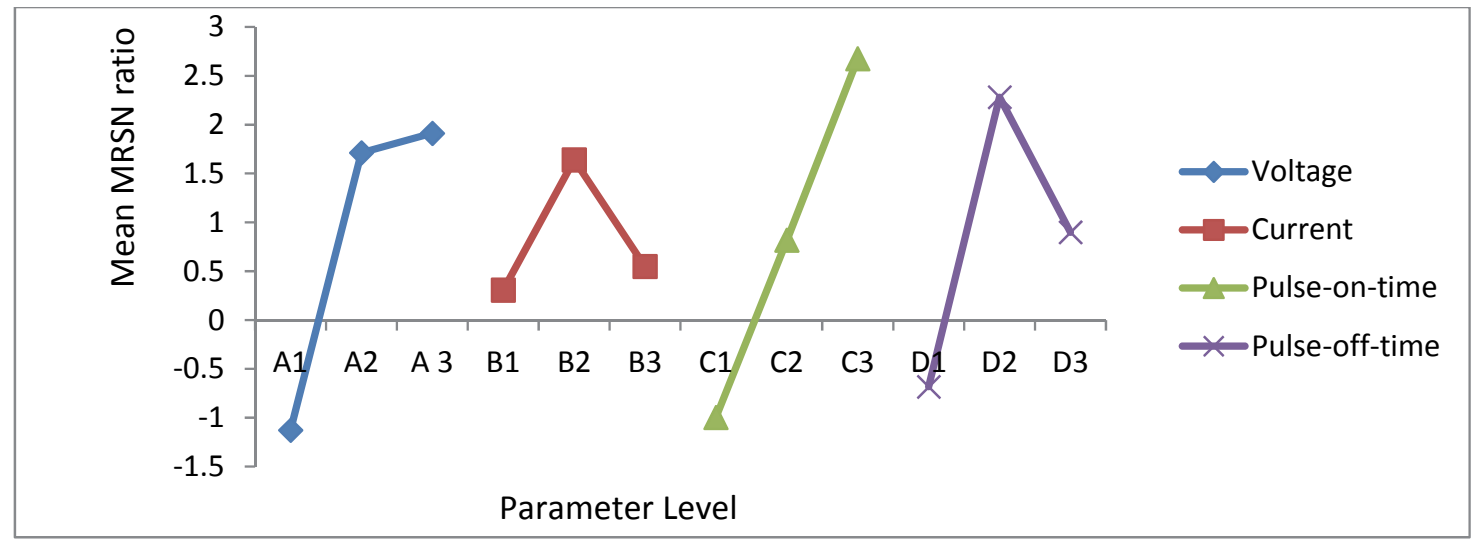

Fig. 3. Response graph of MRSN ratio

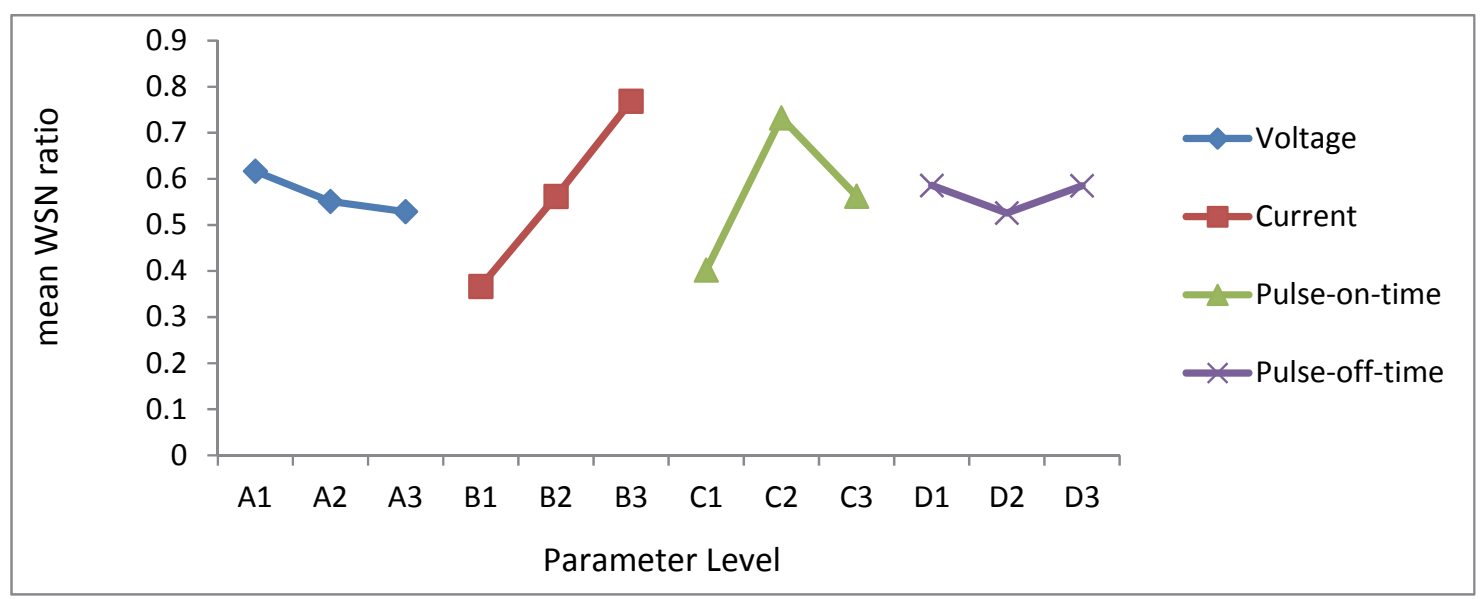

Fig. 4. Response graph of WSN ratio

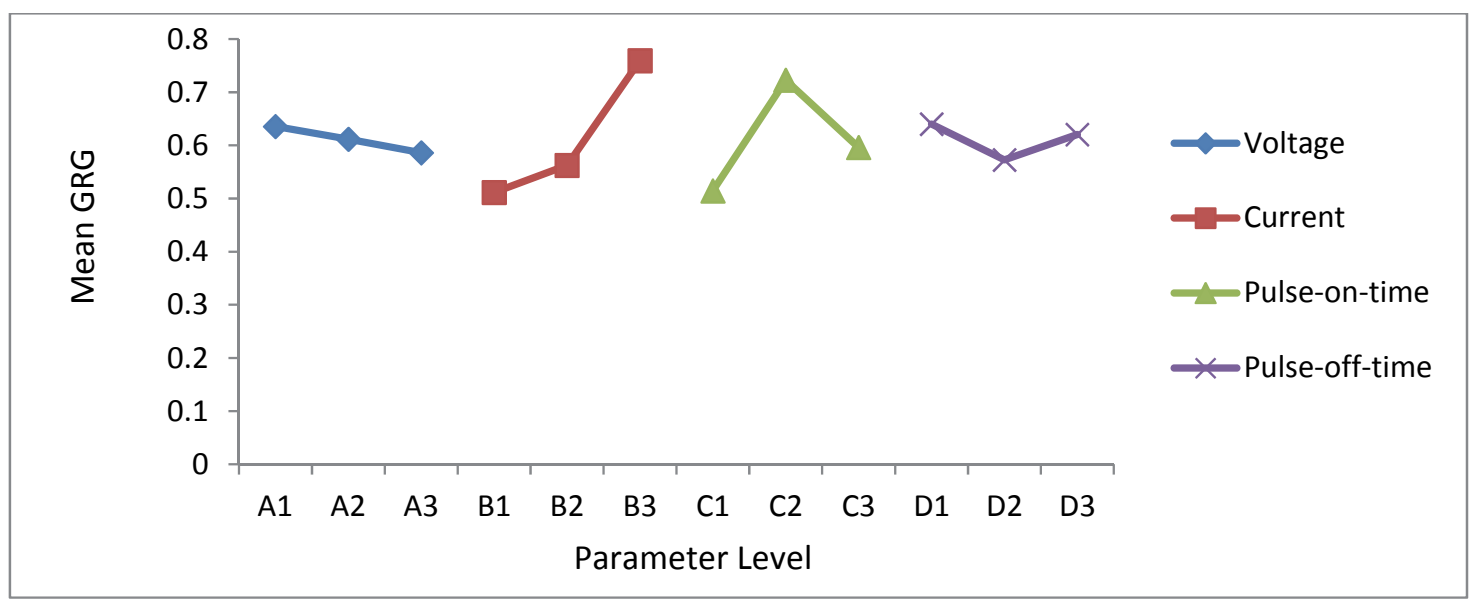

Fig. 5. Response graph of grey relational grade (GRG) 


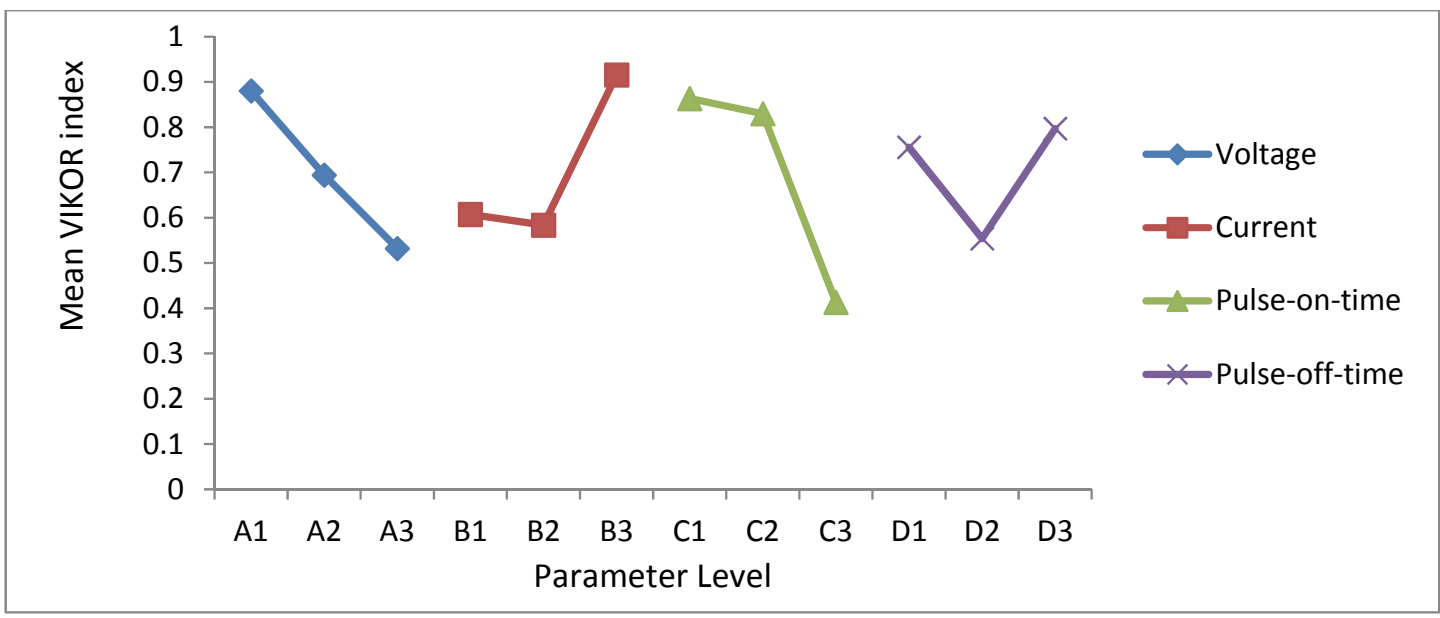

Fig. 6. Response graph of VIKOR index

Table 8 and Table 9 give the results of ANOVA analysis for MRSN, WSN, GRG, and VIKOR index respectively, which was conducted to determine the significant level of variables and it shows the sum of squares (SS) of each variable, its degree of freedom (DF), mean sum of squares $\left(\mathrm{SS}_{\mathrm{m}}\right), \mathrm{F}$ ratios and their corresponding percentage of contribution.

Table 8

Results of ANOVA for MRSN, and WSN

\begin{tabular}{|c|c|c|c|c|c|c|c|c|c|c|}
\hline $\begin{array}{l}\text { Sources of } \\
\text { variance }\end{array}$ & $\begin{array}{l}\text { MRSN } \\
\text { SS }\end{array}$ & DF & $\mathrm{SS}_{\mathrm{m}}$ & $F$ & $\mathrm{P}(\%)$ & $\begin{array}{l}\text { WSN } \\
\text { SS } \\
\end{array}$ & DF & $\mathrm{SS}_{\mathrm{m}}$ & $F$ & $\mathrm{P}(\%)$ \\
\hline $\mathrm{A}$ & 17.3398 & 2 & 8.6699 & 5.7428 & 32.24 & 0.0125 & 2 & 0.0062 & 1.7714 & 2.91 \\
\hline B & 3.0193 & 2 & 1.5097 & 1 & 5.61 & 0.2421 & 2 & 0.1211 & 34.6 & 56.91 \\
\hline $\mathrm{C}$ & 20.2241 & 2 & 10.1121 & 6.6981 & 37.61 & 0.164 & 2 & 0.082 & 23.4286 & 38.53 \\
\hline D & 13.1994 & 2 & 6.5997 & 4.3715 & 24.54 & 0.0071 & 2 & 0.0035 & 1 & 1.65 \\
\hline Error & B & - & - & - & - & D & - & - & - & - \\
\hline Total & 53.7826 & 8 & - & - & 100 & 0.4257 & 8 & - & - & 100 \\
\hline
\end{tabular}

Table 9

Results of ANOVA for GRG, and VIKOR

\begin{tabular}{|c|c|c|c|c|c|c|c|c|c|c|}
\hline $\begin{array}{l}\text { Sources of } \\
\text { variance }\end{array}$ & $\begin{array}{l}\text { GRG } \\
\text { SS }\end{array}$ & DF & $\mathrm{SS}_{\mathrm{m}}$ & $F$ & $\mathrm{P}(\%)$ & $\begin{array}{l}\text { VIKOR } \\
\text { SS }\end{array}$ & DF & $\mathrm{SS}_{\mathrm{m}}$ & $F$ & $\mathrm{P}(\%)$ \\
\hline $\mathrm{A}$ & 0.0037 & 2 & 0.0018 & 1 & 2 & 0.1821 & 2 & 0.0911 & 1.8004 & 21.03 \\
\hline B & 0.1027 & 2 & 0.0514 & 28.5556 & 57.17 & 0.2056 & 2 & 0.1028 & 2.0316 & 23.73 \\
\hline $\mathrm{C}$ & 0.0662 & 2 & 0.0331 & 18.3889 & 36.83 & 0.3773 & 2 & 0.1887 & 3.7292 & 43.56 \\
\hline D & 0.0072 & 2 & 0.0036 & 2 & 4 & 0.1013 & 2 & 0.0506 & 1 & 11.68 \\
\hline Error & A & - & - & - & - & D & - & - & - & - \\
\hline Total & 0.1798 & 8 & - & - & 100 & 0.8663 & 8 & - & - & 100 \\
\hline
\end{tabular}

It is observed from Tab. 8 and 9 that factor B i.e. current, is the most influencing one with respect to the WSN ratio, and GRG values, whereas, factor $\mathrm{C}$ i.e. pulse-on-time, is the most significant parameter with respect to the MRSN ratio and VIKOR index value.

\subsubsection{Validation of the results}

The predicted optimal values of the $\mathrm{S} / \mathrm{N}$ ratios $\left(\eta_{\text {opt }}\right)$ using the optimum level of process parameters can be calculated as: (Nayak \& Rana, 2016)

$$
\eta_{\text {opt }}=\eta_{m}+\sum_{i=1}^{q}\left(\overline{\eta_{l}}-\eta_{m}\right)
$$

where, $\eta_{m}$ is the grand mean of PPI values, $\bar{\eta}_{l}$ is the mean PPI value at the optimum level, and $q$ is the number of the machining parameters that significantly affect the multiple response characteristics. Using multiple regression analysis, the prediction models for MRR, TWR and SR have been obtained to study the correlation among the various input parameters such as voltage (V), current (I), pulse-on- 
time $\left(\mathrm{T}_{\text {on }}\right)$, pulse-off-time $\left(\mathrm{T}_{\text {off }}\right)$ and output responses. The following equations are obtained using the regression analysis:

$$
\begin{aligned}
& M R R=-0.118+0.0077 \mathrm{~V}+0.00735 \mathrm{I}+0.001409 T_{\text {on }}-0.00161 T_{\text {off }} \\
& T W R=-0.95-0.187 \mathrm{~V}+0.0680 \mathrm{I}+0.0189 T_{\text {on }}+0.0307 T_{\text {off }} \\
& S R=21.58-1.832 \mathrm{~V}+0.3482 \mathrm{I}-0.0638 T_{\text {on }}-0.0812 T_{\text {off }}
\end{aligned}
$$

Tables (10-13) show the comparison of predicted PPI value with the actual PPI value obtained from the confirmatory experiments conducted by using the optimal parameter settings. It is observed from these tables that, for the WSN ratio and GRA methods, the material removal rate are increased by $9.31 \%$, the tool wear rate is decreased by $10.18 \%$, and the surface roughness is also decreased by $5.81 \%$, whereas, in case of MRSN ratio and VIKOR methods, there is an overall decrease in all the three performance characteristics. It is clearly seen that, out of these four multiresponse optimization methods, good improvement of MRR, TWR, and SR is obtained by the WSN ratio method with good approximation between the predicted (1.0063) and the experimental value (1) of the mean WSN ratio.

\section{Table 10}

Results of the confirmatory experiment for MRSN ratio method

\begin{tabular}{llcc}
\hline & Initial factor setting & \multicolumn{2}{c}{ Optimal parameter combination } \\
\cline { 2 - 4 } & & Prediction & Experiment \\
\hline Level & $\mathrm{A}_{1} \mathrm{~B}_{1} \mathrm{C}_{1} \mathrm{D}_{1}$ & $\mathrm{~A}_{3} \mathrm{~B}_{2} \mathrm{C}_{3} \mathrm{D}_{2}$ & $\mathrm{~A}_{3} \mathrm{~B}_{2} \mathrm{C}_{3} \mathrm{D}_{2}$ \\
MRR $(\mathrm{g} / \mathrm{min})$ & $3.8 \times 10^{-3}$ & 0.1018 & 0.0948 \\
TWR $(\mathrm{g} / \mathrm{min})$ & $2.16 \times 10^{-3}$ & $3.726 \times 10^{-3}$ & $3.4 \times 10^{-3}$ \\
SR $\mu \mathrm{m})$ & 12.178 & 7.768 & 6.835 \\
MRSN & -4.9951 & 6.0111 & 0.8954 \\
\hline
\end{tabular}

\section{Table 11}

Results of the confirmatory experiment for WSN ratio method

\begin{tabular}{llcc} 
& & \multicolumn{2}{c}{ Optimal parameter combination } \\
\cline { 2 - 4 } & Initial factor setting & Prediction & Experiment \\
\hline Level & $\mathrm{A}_{1} \mathrm{~B}_{1} \mathrm{C}_{1} \mathrm{D}_{1}$ & $\mathrm{~A}_{1} \mathrm{~B}_{3} \mathrm{C}_{2} \mathrm{D}_{1}$ & $\mathrm{~A}_{1} \mathrm{~B}_{3} \mathrm{C}_{2} \mathrm{D}_{1}$ \\
MRR $(\mathrm{g} / \mathrm{min})$ & $3.8 \times 10^{-3}$ & 0.1117 & 0.1221 \\
TWR $(\mathrm{g} / \mathrm{min})$ & $2.16 \times 10^{-3}$ & $3.4735 \times 10^{-3}$ & $3.12 \times 10^{-3}$ \\
$\mathrm{SR}(\mu \mathrm{m})$ & 12.178 & 13.748 & 12.949 \\
WSN & 0.2741 & 1.0063 & 1 \\
\hline
\end{tabular}

Table 12

Results of the confirmatory experiment for GRA method

\begin{tabular}{llll}
\hline & Initial factor setting & & Optimal cutting parameters \\
\cline { 3 - 4 } & & Prediction & Experiment \\
\hline Level & $\mathrm{A}_{1} \mathrm{~B}_{1} \mathrm{C}_{1} \mathrm{D}_{1}$ & $\mathrm{~A}_{1} \mathrm{~B}_{3} \mathrm{C}_{2} \mathrm{D}_{1}$ & $\mathrm{~A}_{1} \mathrm{~B}_{3} \mathrm{C}_{2} \mathrm{D}_{1}$ \\
$\mathrm{MRR}(\mathrm{g} / \mathrm{min})$ & $3.8 \times 10^{-3}$ & 0.1117 & 0.1221 \\
$\mathrm{TWR}(\mathrm{g} / \mathrm{min})$ & $2.16 \times 10^{-3}$ & $3.4735 \times 10^{-3}$ & $3.12 \times 10^{-3}$ \\
$\mathrm{SR}(\mu \mathrm{m})$ & 12.178 & 13.748 & 12.949 \\
$\mathrm{GRG}$ & 0.4682 & 0.9243 & 1 \\
\hline
\end{tabular}

\begin{tabular}{|c|c|c|c|}
\hline & \multirow{2}{*}{ Initial factor setting } & \multicolumn{2}{|c|}{ Optimal cutting parameters } \\
\hline & & Prediction & Experiment \\
\hline Level & $\mathrm{A}_{1} \mathrm{~B}_{1} \mathrm{C}_{1} \mathrm{D}_{1}$ & $\mathrm{~A}_{3} \mathrm{~B}_{2} \mathrm{C}_{3} \mathrm{D}_{2}$ & $\mathrm{~A}_{3} \mathrm{~B}_{2} \mathrm{C}_{3} \mathrm{D}_{2}$ \\
\hline $\operatorname{MRR}(\mathrm{g} / \mathrm{min})$ & $3.8 \times 10^{-3}$ & 0.1018 & 0.0948 \\
\hline $\mathrm{TWR}(\mathrm{g} / \mathrm{min})$ & $2.16 \times 10^{-3}$ & $3.726 \times 10^{-3}$ & $3.4 \times 10^{-3}$ \\
\hline $\mathrm{SR}(\mu \mathrm{m})$ & 12.178 & 7.768 & 6.835 \\
\hline VIKOR index & 1 & -0.0234 & 0 \\
\hline
\end{tabular}

Table 13

Results of the confirmatory experiment for VIKOR method 


\section{Conclusion}

The results obtained from the present experimental analysis are summarized as follows:

1. From the confirmation test, it is found that out of the four methods, WSN ratio method gives better overall quality under the optimal condition derived as compared to other methods. Also the percentage error between the predicted value and the experimental value is very low (i.e. $0.63 \%$ ) in case of WSN ratio method.

2. A voltage of $1 \mathrm{~V}$, current of $15 \mathrm{~A}$, pulse-on-time of $125 \mu \mathrm{s}$, and pulse-off-time of $40 \mu \mathrm{s}$, are recommended as optimal machining parameters for the given EDM operation for the maximization of MRR, and minimization of TWR and SR simultaneously.

3. Through ANOVA analysis, the percentage contribution of the machining parameters to the EDM process is found to be in the sequence of, current, pulse-on-time, voltage, and pulse-off-time. The current is found to be the most significant factor as it has the maximum percentage of contribution $(56.91 \%)$ and pulse-off-time has the least effect (1.64\%) on the EDM operation.

\section{Acknowledgments}

The authors would like to thank the Department of Mechanical Engineering, Veer Surendra Sai University of Technology and CIPET, Bhubaneswar for their support and co-operation to carry out the experimental work.

\section{References}

Balasubramanian, P., \& Senthilvelan, T. (2014). optimization of machining parameters in EDM process using cast and sintered copper electrodes.Procedia Materials Science, 6, 1292-1302.

Chiang, K. T., Chang, F. P., \& Tsai, D. C. (2007). Modeling and analysis of the rapidly resolidified layer of SG cast iron in the EDM process through the response surface methodology. Journal of Materials Processing Technology,182(1), 525-533.

Das, M. K., Kumar, K., Barman, T. K., \& Sahoo, P. (2014). Application of artificial bee colony algorithm for optimization of MRR and surface roughness in EDM of EN31 tool steel. Procedia Materials Science, 6, 741-751.

Dewangan, S., Biswas, C. K., \& Gangopadhyay, S. (2014). Optimization of the Surface Integrity Characteristics of EDM Process using PCA based Grey Relation Investigation. Procedia Materials Science, 6, 1091-1096.

Dhar, S., Purohit, R., Saini, N., Sharma, A., \& Kumar, G. H. (2007). Mathematical modeling of electric discharge machining of cast $\mathrm{Al}-4 \mathrm{Cu}-6 \mathrm{Si}$ alloy-10wt.\% SiC P composites. Journal of Materials Processing Technology, 194(1), 24-29.

Kackar, R. N. (1989). Off-line quality control, parameter design, and the Taguchi method. In Quality Control, Robust Design, and the Taguchi Method(pp. 51-76). Springer US.

Montgomery DC. (2001). Design and analysis of experiments, $5^{\text {th }}$ edn, Wiley, Singapore.

Mandal, D., Pal, S. K., \& Saha, P. (2007). Modeling of electrical discharge machining process using back propagation neural network and multi-objective optimization using non-dominating sorting genetic algorithm-II.Journal of Materials Processing Technology, 186(1), 154-162.

Lee, H. T., \& Liu, C. (2009). Optimizing the EDM hole-drilling strain gage method for the measurement of residual stress. Journal of Materials Processing Technology, 209(15), 5626-5635.

Joshi, S. N., \& Pande, S. S. (2010). Thermo-physical modeling of die-sinking EDM process. Journal of manufacturing processes, 12(1), 45-56.

Majumder, A. (2013). Process parameter optimization during EDM of AISI 316 LN stainless steel by using fuzzy based multi-objective PSO. Journal of Mechanical Science and Technology, 27(7), 2143-2151. 
Mohanty, C. P., Mahapatra, S. S., \& Singh, M. R. (2016). An intelligent approach to optimize the EDM process parameters using utility concept and QPSO algorithm. Engineering Science and Technology, an International Journal.

Nayak, I., \& Rana, J. (2016). Selection of a suitable multiresponse optimization technique for turning operation. Decision Science Letters, 5(1), 129-142.

Puertas, I., \& Luis, C. J. (2012). Optimization of EDM conditions in the manufacturing process of B4C and WC-Co conductive ceramics. The International Journal of Advanced Manufacturing Technology, 59(5-8), 575-582.

Raja, S. B., Pramod, C. S., Krishna, K. V., Ragunathan, A., \& Vinesh, S. (2015). Optimization of electrical discharge machining parameters on hardened die steel using Firefly Algorithm. Engineering with Computers,31(1), 1-9.

Rangajanardhaa, G., \& Rao, S. (2009). Development of hybrid model and optimization of surface roughness in electric discharge machining using artificial neural networks and genetic algorithm. Journal of materials processing technology, 209(3), 1512-1520.

Sengottuvel, P., Satishkumar, S., \& Dinakaran, D. (2013). Optimization of multiple characteristics of EDM parameters based on desirability approach and fuzzy modeling. Procedia Engineering, 64, 1069-1078.

Singh, P. N., Raghukandan, K., \& Pai, B. C. (2004). Optimization by grey relational analysis of EDM parameters on machining Al-10\% SiC P composites. Journal of Materials Processing Technology, 155, 1658-1661.

Teimouri, R., \& Baseri, H. (2014). Optimization of magnetic field assisted EDM using the continuous ACO algorithm. Applied Soft Computing, 14, 381-389.

Tzeng, Y. F., \& Chiu, N. H. (2003). Two-phase parameter design for the optimisation of the electricaldischarge machining process using a Taguchi dynamic experiment. The International Journal of Advanced Manufacturing Technology, 21(12), 1005-1014.

Tzeng, Y. F., \& Chen, F. C. (2007). Multi-objective optimisation of high-speed electrical discharge machining process using a Taguchi fuzzy-based approach. Materials \& Design, 28(4), 1159-1168.

Wang, Y., Zhou, X. J., \& Hu, D. J. (2006). An experimental investigation of dry-electrical discharge assisted truing and dressing of metal bonded diamond wheel. International Journal of Machine Tools and Manufacture,46(3), 333-342.

Yang, S. H., Srinivas, J., Mohan, S., Lee, D. M., \& Balaji, S. (2009). Optimization of electric discharge machining using simulated annealing.Journal of Materials Processing Technology, 209(9), 44714475 .

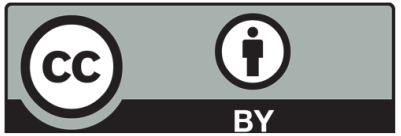

(C) 2017 by the authors; licensee Growing Science, Canada. This is an open access article distributed under the terms and conditions of the Creative Commons Attribution (CC-BY) license (http://creativecommons.org/licenses/by/4.0/). 